\title{
Central Laboratory
}

National Cancer Institute

\section{Source}

National Cancer Institute. Central Laboratory. NCI Thesaurus. Code C64207.

A laboratory delivering the data for a particular study. 